\title{
A Comparative Study of Pigmented and Non-pigmented Basal Cell Carcinoma in Reflectance Confocal Microscopy
}

\author{
ANNA POGORZELSKA-ANTKOWIAK ${ }^{1}$, SŁAWOMIR GRZEGORCZYN ${ }^{2}$, \\ PAOLA CORNELI ${ }^{3}$ and JACEK C. SZEPIETOWSKI ${ }^{4}$ \\ ${ }^{1}$ EsteDerm Private Dermatolgy Clinic, Tychy, Poland; \\ ${ }^{2}$ Department of Biophysics, Medical University of Silesia, Zabrze, Poland; \\ ${ }^{3}$ Department of Dermatology, Ospedale Maggiore di Trieste, Trieste, Italy; \\ ${ }^{4}$ Department of Dermatology, Venereology and Allergology, Wroclaw Medical University, Wroclaw, Poland
}

\begin{abstract}
Background/Aim: Basal cell carcinoma (BCC) is a common skin cancer, especially in the elderly population. The probability of $B C C$ development increases past the age of 55. Dermoscopy and reflectance confocal microscopy $(R C M)$ are two modern tools useful in the diagnosis of BCC. Patients and Methods: This is a retrospective study conducted on a group of 21 patients with a confirmed diagnosis of BCC. All patients were examined by dermoscopy and RCM. Dermoscopic images were taken using a videodermoscope. RCM was performed in three layers: epidermal, dermoepidermal junction (DEJ), and superficial dermal layer. In each layer, a few RCM criteria of basal cell carcinoma diagnosis were taken into consideration. Results: Dermoscopy of pigmented BCCs revealed blue globules of pigment $(p<0.05)$, gray and blue ovoid nests, which were absent in the entire non-pigmented carcinomas group. In $R C M$, the epidermis showed no differences between pigmented and non-pigmented carcinomas, however, significant differences were observed at the DEJ. In pigmented BCCs, cordlike structures and plump atypical cells were observed $(p<0.05)$, while in non-pigmented carcinomas, dark silhouettes were present $(p<0.05)$. Conclusion: To our knowledge, that is the first study comparing features between pigmented and non-pigmented BCC by RCM. Pigmented and non-pigmented BCCs presented different features in both
\end{abstract}

This article is freely accessible online.

Correspondence to: Prof. Dr. Jacek C. Szepietowski, Department of Dermatology, Venereology and Allergology, Wroclaw Medical University, Chalubinskiego 1, 50-368 Wroclaw, Poland. Tel: +48 717842286, Fax: +48 713270942, e-mail: jacek.szepietowski@ umed.wroc.pl

Key Words: Confocal microscopy, dermoscopy, skin cancer, pigmented carcinoma, diagnosis. dermoscopy and RCM. Furthermore, RCM revealed more discriminating features at the DEJ than dermoscopy, thus can be more efficient in the differential diagnosis of difficult BCC.

Basal cell carcinoma (BCC) is one of the most common skin cancers, especially in the elderly population and there has been an increase in its incidence in recent years. The probability of development increases past the age of 55 (1). Sun exposure, ionizing radiation, arsenic, and psoralens are the most important risk factors $(2,3)$. Clinically and histologically, BCC has been classified into five subtypes: superficial, nodular, morpheaform, infundibulocystic, and fibroepithelial tumor of Pinkus (4). The most common subtype, the nodular, occurs in many cases as a pinkish papule or nodule with a pearl border and telangiectasia and sometimes there is ulceration in the central part of the lesion. The superficial subtype is the second most common one, and clinically, it appears as a pinkish plaque mostly located on the trunk (5). All subtypes, especially nodular ones, can reveal pigment and lead us to misdiagnosis of melanoma.

Dermoscopy and reflectance confocal microscopy (RCM) are two non-invasive tools useful for BCC diagnosis. Nori et al. found that RCM is sensitive and accurate for in vivo diagnosis of $\mathrm{BCC}$, indicating the presence of polarized nuclei as one of five RCM diagnostic criteria for $\operatorname{BCC}(6,7)$. The remaining four criteria (elongated monomorphic nuclei, pleomorphic epidermis, increased vasculature, and whole blood cell count) constitute the best compromise between high sensitivity and high specificity for BCC (6). This study aimed to compare the features of pigmented and nonpigmented BCC in dermoscopy and RCM.

\section{Patients and Methods}

Patients. The study was performed according to the Declaration of Helsinki. All patients gave the informed consent to participate in the study. The entire group of 21 patients with histopathologically 
Table I. Demographic patients' characteristics.

\begin{tabular}{lc}
\hline Feature & $\mathrm{n}(\%)$ \\
\hline Total number of patients & 21 \\
Male & $6(28.6)$ \\
Female & $15(71.4)$ \\
Mean age & $63.1(32$ to 79$)$ \\
Location & \\
Head & $16(76.2)$ \\
Trunk & $3(14.3)$ \\
Limbs & $2(9.5)$ \\
Fitzpatrick's skin type & \\
I & $3(14.3)$ \\
II & $18(85.7)$ \\
BCC subtype & $6(28.6)$ \\
Nodular & $15(71.4)$ \\
Superficial & $11(52.4)$ \\
Pigmented & $10(47.6)$ \\
Non-pigmented & \\
\hline
\end{tabular}

BCC, Basal cell carcinoma.

Table II. Comparison of dermoscopic features between pigmented and non-pigmented basal cell carcinoma (BCC).

\begin{tabular}{lccc}
\hline Features & $\begin{array}{c}\text { Pigmented } \\
\text { BCC (n=11) } \\
\mathrm{n}(\%)\end{array}$ & $\begin{array}{c}\text { Non-pigmented } \\
\text { BCC (n=10) } \\
\mathrm{n}(\%)\end{array}$ & $p$-Value \\
\hline Telangiectasia & $11(52.4)$ & $10(47.6)$ & $\mathrm{ns}$ \\
Blue globules & $10(47.6)$ & $0(0)$ & $\mathbf{< 0 . 0 5}$ \\
Grey or blue ovoid nests & $4(19)$ & $0(0)$ & $\mathrm{ns}$ \\
Leaf like structures & $1(4.8)$ & $0(0)$ & $\mathrm{ns}$ \\
Structureless area & $2(9.5)$ & $4(19)$ & $\mathrm{ns}$ \\
Ulceration & $2(9.5)$ & $0(0)$ & $\mathrm{ns}$ \\
Pseudocysts & $3(14.3)$ & $1(4.8)$ & $\mathrm{ns}$ \\
\hline
\end{tabular}

Statistically significant $p$-values are shown in bold.

confirmed BCC in the Private Dermatology Clinic, Tychy, Poland between 2017-2020, was retrospectively enrolled in the study. There were 15 female and 6 male patients. Nodular BCC was diagnosed in 6 patients, while the remaining 15 had superficial BCC type. The mean age of the patients was 63.04 years (range=32-79) with a mean of 65.5 and 60.3 years in the pigmented and the nonpigmented BCC groups, respectively. The demographic characteristics of the patients are presented in Table I, with 10 BCCs being non-pigmented and 11 pigmented.

Dermoscopy and RCM. Dermoscopic images were taken using a contact FotoFinder videodermoscope (FotoFinder Systems GmbH, Bad Birnbach, Germany). In dermoscopy, presence of many features such as globules, macules, leaf-like structures, vessels, ulceration, and pseudocysts were assessed. Confocal images were obtained with a reflectance confocal microscope Vivascope ${ }^{\circledR} 1500$ (Lucid Inc., Rochester, NY, USA), which was equipped with a diode laser of 830 $\mathrm{nm}$. Immersion was used to obtain the right fixation of the lens to
Table III. Comparative reflectance confocal microscopic features in the epidermis and the dermo-epidermal junction between pigmented and non-pigmented basal cell carcinoma (BCC).

\begin{tabular}{lccc}
\hline Feature & $\begin{array}{c}\text { Pigmented } \\
\text { BCC }\end{array}$ & $\begin{array}{c}\text { Non-pigmented } \\
\text { BCC }\end{array}$ & $p$-Value \\
& $\mathrm{n}(\%)$ & $\mathrm{n}(\%)$ & \\
Epidermis & $11(52.4)$ & $10(47.6)$ & $\mathrm{ns}$ \\
$\quad$ Honey combed pattern & $8(38.1)$ & $9(42.8)$ & $\mathrm{ns}$ \\
$\begin{array}{l}\text { Streaming locally } \\
\quad \text { polarization) }\end{array}$ & $7(33.3)$ & $5(23.8)$ & $\mathrm{ns}$ \\
Dendritic cells & $2(9.5)$ & 0 & $\mathrm{~ns}$ \\
Ulceration & $3(14.3)$ & $1(4.8)$ & $\mathrm{ns}$ \\
Other features-corneal & & & \\
$\quad$ pseudocysts & & & \\
Dermo-epidermal junction & $11(52.4)$ & 0 & $\mathbf{< 0 . 0 5}$ \\
$\quad$ Cordlike structures & $8(38.1)$ & $3(14.3)$ & $\mathrm{ns}$ \\
Clefting & $11(52.4)$ & $10(47.6)$ & $\mathrm{ns}$ \\
$\quad$ Nonspecific pattern & $1(4.8)$ & $10(47.6)$ & $\mathbf{< 0 . 0 5}$ \\
Dark silhouettes & $11(52.4)$ & $10(47.6)$ & $\mathrm{ns}$ \\
Canalicular vessels & $6(28.6)$ & 0 & $\mathbf{< 0 . 0 5}$ \\
Large atypical cells & & & \\
$\quad$ close to nests & & & \\
\hline
\end{tabular}

Statistically significant $p$-values are shown in bold.

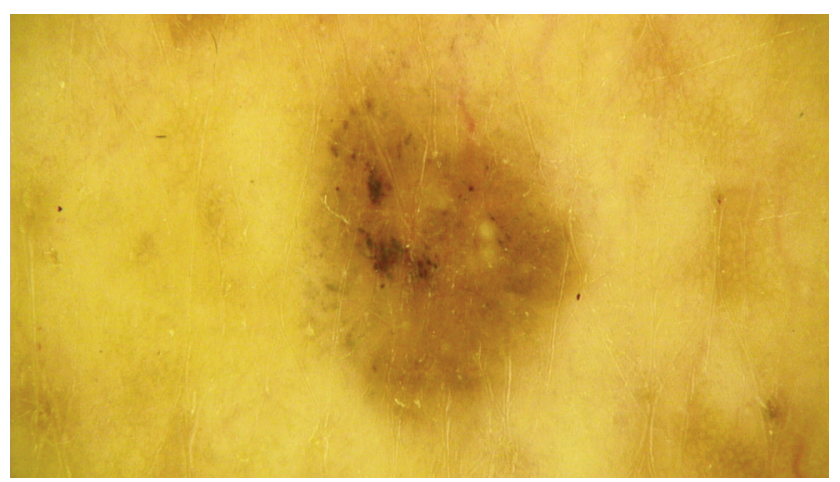

Figure 1. Dermoscopic image of pigmented basal cell carcinoma with blue globules in the left part of the lesion.

the skin. Three mosaics $(500 \times 500 \mu \mathrm{m})$ were made for each lesion and included three skin levels: superficial epidermal layer, the dermo-epidermal junction (DEJ), and the upper dermis. In the epidermis, the presence of atypical cells, streaming of keratinocytes (polarization), dendritic cells, ulceration, or corneal cysts were assessed. In the DEJ, atypical cells, nodular islands (cordlike structures or dark silhouettes), clefting and dilated, branched, canalicular vessels were detected. In dermoscopy, presence of typical BCC features and pigmentation was evaluated.

Statistical analysis. Statistical calculations were carried out using the Statistica 13.1 software (StatSoft, Inc., Tulsa, OK, USA). Statistical differences between pigmented and non-pigmented BCC variables were calculated using the Fisher's exact test for tables $2 \times 2$, the given $p$-values in the tables were calculated for a two-tailed 


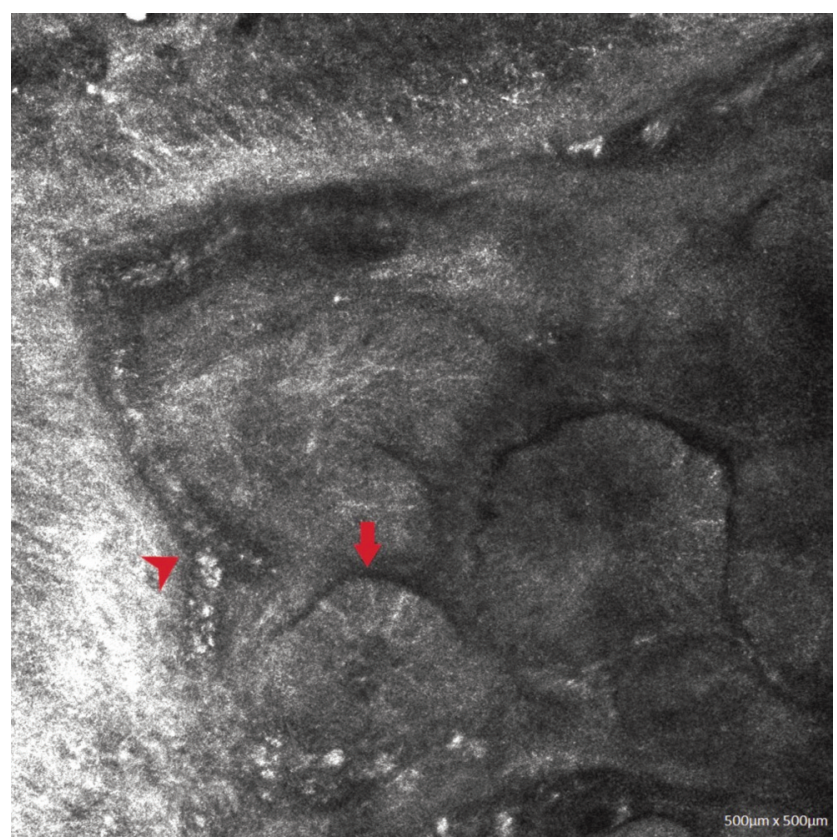

Figure 2. Reflectance confocal microscopy image showing bright cordlike structures with clefting (arrow) and elongated vessels (arrowhead) in the border, in pigmented basal cell carcinoma.

test. The significance level for differences between variables was adopted as $\mathrm{a}=0.05$.

\section{Results}

Dermoscopic features. Dermoscopic features are listed in Table II. Dermoscopically, only 6 lesions were a pinkish nodule or tumor, while 15 revealed features of superficial BCC. Telangiectasia was present in all examined lesions. Central part ulceration was seen in 2 pigmented carcinomas, while that feature was not observed in any of the nonpigmented BCC.

Notably, 10 among 11 pigmented carcinomas revealed blue globules of pigment (Figure 1), while, this feature was absent in all the non-pigmented BCC. The difference between the two groups was significant $(p<0.05$, Table II). Furthermore, 4 pigmented lesions showed grey and blue ovoid nests, while non-pigmented BCC did not present such features; however, the difference was not statistically significant (Table II). Four BCCs (3 pigmented lesions and 1 non-pigmented) exhibited pseudocysts. All superficial carcinomas showed telangiectasia with typical arborizing vessels. The mean diameter of all BCCs was $4.6 \mathrm{~mm}$ (range=2-7).

RCM features. RCM features are presented in Table III. In all carcinomas, the epidermis had typical architecture

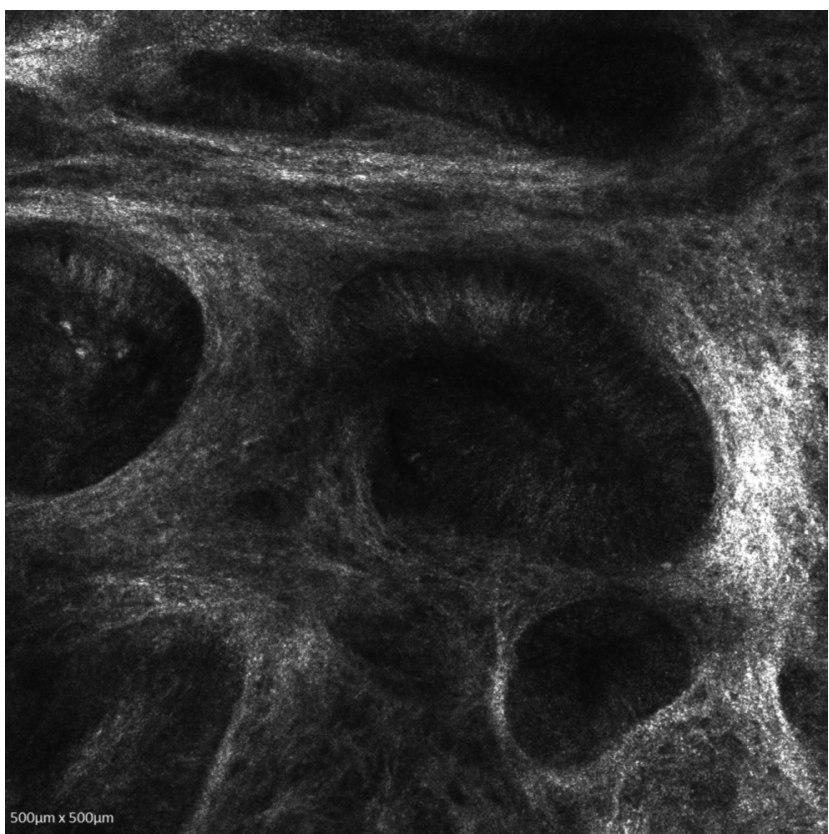

Figure 3. Reflectance confocal microscopy image showing dark silhouettes in non-pigmented basal cell carcinoma.

consisting of honeycombed pattern with focal streaming. Few dendritic cells were spreading the epidermis in all lesions. The differences between pigmented and nonpigmented BCC were observed in the DEJ. Cordlike structures were present in all pigmented carcinomas $(p<0.05$; Figure 2 and Table III). Clefting, mostly connected with tumor islands, was noted in 8 pigmented carcinomas. Notably, all non-pigmented carcinomas showed dark silhouettes (Figure 3), but this was only present in one pigmented $\mathrm{BCC}$, and this feature was statistically significantly different between pigmented and nonpigmented BCC $(p<0.05$; Table III). Six pigmented BCCs revealed large atypical cells in the surrounding nests, while large atypical cells in surrounding nests were not observed in non-pigmented BCCs $(p<0.05$; Table III). Canalicular vessels observed in dermoscopy as arborizing ones were seen in all BCCs, especially next to the tumor islands (Table III). They were elongated and in a horizontal arrangement.

\section{Discussion}

BCC can usually be diagnosed by clinical or dermoscopic examination. In our study, by dermoscopy, blue globules were significant for pigmented $\mathrm{BCC}$ diagnosis and this was also the case for cordlike structures at the DEJ by RCM, as well as absence of dark silhouettes. Therefore, RCM can help differentiate more suspicious lesions, especially when 
variegating between pigmented BCC and melanoma (8-10). The diagnostic accuracy of RCM in BCC diagnosis has been previously described by Giutera et al.; they estimated the sensitivity at $100 \%$ and specificity at $88.5 \%$ (7). However, Gonzales et al. were the first to describe major confocal criteria for BCC diagnosis (11). Their results were based on eight BCCs and showed polarization of keratinocytes and dilated vessels. Further studies also showed that the presence of some features such as peripheral palisading, solar elastosis, and size of tumor nests might be significant in distinguishing nodular and superficial BCC (12-14). Later, Farnetani et al. highlighted crucial RCM diagnostic criteria for basal cell carcinoma (3). They established basaloid cordlike structures, presence of ulceration, and nonspecific DEJ pattern as RCM criteria for recognition of BCC. Therefore, according to the literature presented, we conclude that RCM may permit in vivo diagnosis of BCC, especially pigmented, clinically suggestive of melanoma.

To our knowledge, no study focusing and describing differences between pigmented and non-pigmented BCC by RCM has been published so far, although Agero et al. indicated that pigmented BCCs were predominantly nodular (15). Furthermore, RCM revealed cordlike structures, polypoid islands, or nodules with the presence of bright dendritic cells, reflecting the histological tumor growth pattern surrounded by dark non-refractile cleftlike dark spaces.

In our study, the majority of pigmented BCCs were superficial. In all carcinomas, pigmented and non-pigmented, a honeycombed pattern was partially preserved. Local streaming was seen in all cases. Dendritic cells observed in the epidermis, both pigmented and non-pigmented BCC, corresponded probably to Langerhans cells. Likewise, long, thin dendritic cells in the epidermis overlying tumor have been previously described (10). Notably, the DEJ revealed differences between pigmented and non-pigmented carcinomas. Bright dendritic cells within tumor islands in BCCs were present. Additionally, we showed that densely packed atypical cells of the tumors formed cordlike structures. Thus, our findings are in accordance with those by Gonzales et al., who first indicated that bright dendritic cells could represent melanocytes in pigmented BCCs (11). Bright, plump cells, likely to be melanophages, were seen between cordlike structures in 6 of 11 pigmented BCCs.

Non-pigmented carcinomas revealed numerous dark silhouettes in the DEJ, while, small dark silhouettes were observed in only one pigmented carcinoma. Clefting being the next feature of BCC in our study was more common in pigmented carcinomas. This feature was found in 8 pigmented BCCs and three non-pigmented ones. All analyzed BCCs abounded with canalicular vessels corresponding to arborizing vessels visible in dermoscopy. They had mainly horizontal orientation and were located close to tumor islands.
In conclusion, to the best of our knowledge, this is the first study comparing features between pigmented and nonpigmented BCC by dermoscopy as well as by RCM. Pigmented and non-pigmented BCCs presented different features in both dermoscopy and RCM. Furthermore, RCM revealed more discriminating features than dermoscopy, thus it can be more efficient in the differential diagnosis of both lesions. The presence of blue globules in dermoscopy indicated pigmented BCC. Cordlike structures and bright, plump atypical cells located close to tumor islands at the DEJ were also characteristic for pigmented BCC, in contrast to the incidence of dark silhouettes, which was significantly higher in non-pigmented carcinomas. Consequently, RCM is useful in diagnosing subtypes of $\mathrm{BCC}$, as it enables the examination of the BCC distinctive features at the DEJ.

\section{Conflicts of Interest}

Authors declare that they have no conflicts of interest, and no funding was supporting that study.

\section{Authors' Contributions}

Anna Pogorzelska-Antkowiak: Data collection and interpretation, writing the manuscript. Sławomir Grzegorczyn: Statistical analysis, data interpretation. Paola Corneli: Data interpretation, critical revision of the manuscript. Jacek C. Szepietowski: Critical revision of the manuscript, final manuscript approval.

\section{References}

1 Lupu M, Popa IM, Voiculescu VM, Caruntu A and Caruntu C: A systematic review and meta-analysis of the accuracy of in vivo reflectance confocal microscopy for the diagnosis of primary basal cell carcinoma. J Clin Med 8(9): 1462, 2019. PMID: 31540342. DOI: $10.3390 /$ jcm8091462

2 Moscarella E, Rabinovitz H, Oliviero MC, Brown L, Longo C, Zalaudek I, Piana S, Farnetani F, Lallas A, Argenziano G and Pellacani G: The role of reflectance confocal microscopy as an aid in the diagnosis of collision tumors. Dermatology 227(2): 109-117, 2013. PMID: 24080548. DOI: 10.1159/000351771

3 Farnetani F, Scope A, Braun RP, Gonzalez S, Guitera P, Malvehy J, Manfredini M, Marghoob AA, Moscarella E, Oliviero M, Puig S, Rabinovitz HS, Stanganelli I, Longo C, Malagoli C, Vinceti $\mathrm{M}$ and Pellacani G: Skin cancer diagnosis with reflectance confocal microscopy: Reproducibility of feature recognition and accuracy of diagnosis. JAMA Dermatol 151(10): 1075-1080, 2015. PMID: 25993262. DOI: 10.1001/jamadermatol.2015.0810

4 Peppelman M, Wolberink EA, Blokx WA, van de Kerkhof PC, van Erp PE and Gerritsen MJ: In vivo diagnosis of basal cell carcinoma subtype by reflectance confocal microscopy. Dermatology 227(3): 255-262, 2013. PMID: 24158236. DOI: $10.1159 / 000354762$

5 Papageorgiou C, Apalla Z, Variaah G, Matiaki FC, Sotiriou E, Vakirlis E, Lazaridou E, Ioannides D and Lallas A: Accuracy of dermoscopic criteria for the differentiation between superficial basal cell carcinoma and Bowen's disease. J Eur Acad Dermatol 
Venereol 32(11): 1914-1919, 2018. PMID: 29633377. DOI: $10.1111 /$ jdv. 14995

6 Nori S, Rius-Díaz F, Cuevas J, Goldgeier M, Jaen P, Torres A and González S: Sensitivity and specificity of reflectance-mode confocal microscopy for in vivo diagnosis of basal cell carcinoma: a multicenter study. J Am Acad Dermatol 51(6): 923930, 2004. DOI: 10.1016/j.jaad 2004.06.028

7 Guitera P, Menzies SW, Longo C, Cesinaro AM, Scolyer RA and Pellacani G: In vivo confocal microscopy for diagnosis of melanoma and basal cell carcinoma using a two-step method: analysis of 710 consecutive clinically equivocal cases. J Invest Dermatol 132(10): 2386-2394, 2012. PMID: 22718115. DOI: 10.1038/jid.2012.172

8 Charles CA, Marghoob AA, Busam KJ, Clark-Loeser L and Halpern AC: Melanoma or pigmented basal cell carcinoma: a clinical-pathologic correlation with dermoscopy, in vivo confocal scanning laser microscopy, and routine histology. Skin Res Technol 8(4): 282-287, 2002. PMID: 12423549. DOI: 10.1034/j.1600-0846.2002.00353.x

9 Scope A, Mecca PS, Marghoob AA: skINsight lessons in reflectance confocal microscopy: rapid diagnosis of pigmented basal cell carcinoma. Arch Dermatol 145(1): 106-107, 2009. DOI: 10.1001/archdermatol.2008.577

10 Segura S, Puig S, Carrera C, Palou J and Malvehy J: Dendritic cells in pigmented basal cell carcinoma: a relevant finding by reflectance-mode confocal microscopy. Arch Dermatol 143(7): 883-886, 2007. PMID: 17638732. DOI: 10.1001/archderm. 143.7.883

11 González S and Tannous Z: Real-time, in vivo confocal reflectance microscopy of basal cell carcinoma. J Am Acad Dermatol 47(6): 869-874, 2001. PMID: 12451371. DOI: $10.1067 / \mathrm{mjd} .2002 .124690$
12 Longo C, Lallas A, Kyrgidis A, Rabinovitz H, Moscarella E, Ciardo S, Zalaudek I, Oliviero M, Losi A, Gonzalez S, Guitera P, Piana S, Argenziano G and Pellacani G: Classifying distinct basal cell carcinoma subtype by means of dermatoscopy and reflectance confocal microscopy. J Am Acad Dermatol 71(4): 716-724.e1, 2014. PMID: 24928707. DOI: 10.1016/j.jaad.2014.04.067

13 Gulia A, Altamura D, De Trane S, Micantonio T, Fargnoli MC and Peris K: Pigmented reticular structures in basal cell carcinoma and collision tumours. Br J Dermatol 162(2): 442444, 2010. PMID: 19754866. DOI: 10.1111/j.1365-2133.2009. 09460.x

14 Ghita MA, Caruntu C, Rosca AE, Kaleshi H, Caruntu A, Moraru L, Docea AO, Zurac S, Boda D, Neagu M, Spandidos DA and Tsatsakis AM: Reflectance confocal microscopy and dermoscopy for in vivo, non-invasive skin imaging of superficial basal cell carcinoma. Oncol Lett 11(5): 3019-3024, 2016. PMID: 27123056. DOI: 10.3892/ol.2016.4354

15 Agero AL, Busam KJ, Benvenuto-Andrade C, Scope A, Gill M, Marghoob AA, González S and Halpern AC: Reflectance confocal microscopy of pigmented basal cell carcinoma. J Am Acad Dermatol 54(4): 638-643, 2006. PMID: 16546585. DOI: 10.1016/j. jaad.2005.11.1096

Received September 16, 2020

Revised November 5, 2020

Accepted November 19, 2020 